\title{
The meanings of perspectival verbs and their implications on the taxonomy of projective content/conventional implicature
}

\author{
David Y. Oshima \\ Nagoya University
}

\begin{abstract}
This work discusses the presuppositional meanings of three kinds of perspectival (perspective-sensitive) verbs: (i) motion-deictic verbs, (ii) empathy-loaded verbs, and (iii) referent-honorific verbs, and their implications on the taxonomy of "projective content", which subsumes but is not limited to presupposition. Building on Tonhauser, Beaver, Roberts \& Simons's (2013) four-way classification of projective content, I propose a more fine-grained, six-way classification that distinguishes "global-context oriented" content, which obligatorily projects through a "filter" operator such as a belief predicate, and "ambioriented" content, which optionally does so. I also develop a "pseudo-multidimensional" representation of natural language meaning, where (i) proffered content, (ii) nonpresuppositional projective content, and (iii) presuppositional projective content have distinct roles in the sentence meaning, while anaphoric interaction across them is nevertheless possible.
\end{abstract}

Keywords: projective content, conventional implicature, presupposition, deixis, empathy, honorifics

\section{Introduction}

This work discusses the presuppositional meanings of three kinds of perspectival (perspective-sensitive) verbs: (i) motion-deictic verbs (e.g., English go/come), (ii) empathy-loaded verbs (e.g., Japanese yaru/kureru 'give'), and (iii) referent-honorific verbs (e.g., Japanese osumaida 'reside'), and their implications on the taxonomy of "projective content". Building on Tonhauser et al.'s (2013) four-way classification of projective content, I propose a more fine-grained, six-way classification that distinguishes "global-context oriented" content, which obligatorily projects through a "filter" operator such as a belief predicate, and "ambioriented" content, which optionally does so. I also develop a "pseudo-multidimensional" representation of natural language meaning, where three semantic components - (i) proffered content, (ii) nonpresuppositional projective content, and (iii) presuppositional projective content - have distinct roles in the sentence meaning, while anaphoric interaction across them is nevertheless possible. 


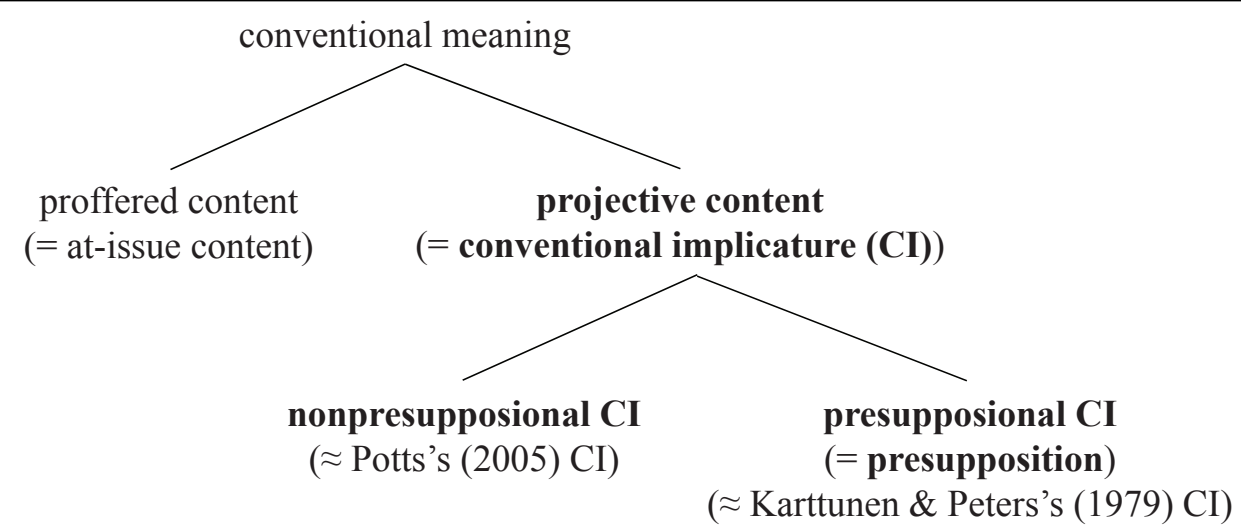

Figure 1 Three types of conventionally coded meaning

\section{Terminological clarification}

It has long been acknowledged that the (conventionally coded) meaning of a natural language sentence can be divided into multiple components (layers, dimensions), one of which is "main", "central", and "foregrounded". Various labels have been applied to the foregrounded and backgrounded components, and some labels, in particular conventional implicature and presupposition, have been used by different ways by different authors. A note on the terminology adopted in this work is thus needed.

After Tonhauser et al. (2013), I use projective content as a cover term for all kinds of the backgrounded meaning, which project through a "hole" operator such as negation, question, and a modal. I refer to the foregrounded meaning, on the other hand, as proffered content or at-issue content.

As will be detailed shortly, projective content can be either presuppositional or nonpresuppositional. The former type, which can be (and most often has been) simply called presupposition, roughly corresponds to what Karttunen \& Peters (1979) call conventional implicature (CI); the latter roughly corresponds to what Potts (2005) calls CI. I use the term CI in a broad sense, and as an alternative label for projective content. See Figure 1 for a summary.

\section{Tonhauser et al.'s (2013) taxonomy}

Tonhauser et al. (2013) propose to classify projective content based on two criteria: (i) whether they are subject to the strong contextual felicity (SCF) constraint, i.e., whether they must have been part of the interlocutors' common ground prior to the utterance, and (ii) whether they have the obligatory local effect (OLE), i.e., whether their projection is necessarily "filtered" by a belief predicate (Table 1). 
The meanings of perspectival verbs

\begin{tabular}{cccl}
\hline classes & SCF & OLE & examples \\
\hline \hline A & + & + & additive implication of $t o o$ \\
\hline B & - & - & appositive, NRRC, expressive \\
\hline C & - & + & prejacent implication of only \\
\hline D & + & - & "indication" implication of a demonstrative \\
\hline
\end{tabular}

Table 1 Tonhauser et al.'s (2013) taxonomy

Projective contents that meet both criteria (i.e., Class A) correspond to paradigmatic presuppositions, and include the additive implication induced by the focus particle too. Due to the SCF constraint, (1) will be felicitous as a reply to (2b) but not as a reply to (2a). Due to the OLE, utterance (3) does not commit the speaker to the truth of 'Somebody other than Ken sang', but rather to the truth of 'Lucy believes that somebody other than Ken sang'.

(1) $\quad[\text { Ken }]_{\mathrm{F}}$ sang, too. $\rightsquigarrow$ 'Somebody other than Ken sang.'

(2) a. I have no idea who sang. Who, if anybody, sang?

b. I heard that John sang. Who else, if anybody, sang?

(3) Lucy believes that $[\text { Ken }]_{F}$ sang, too.

y $\rightarrow$ 'Somebody other than Ken sang.'

$\rightsquigarrow$ 'Lucy believes that somebody other than Ken sang.'

A major advantage of this two-dimensional classification is that it provides natural home for so-called "weak" or "informational" presupposition (e.g., Prince 1978; Birner 2013; cf. Abusch 2002). The prejacent implication of only, for example, is projective but is filtered by a belief predicate, as shown in (5). At the same time, it does not need to be taken for granted in the discourse situation, as evidenced by the observation that (4) can be a felicitous reply to (2a) (see Beaver \& Clark 2008 for discussion). Under Tonhauser et al.'s taxonomy, it can be understood to be a "Class C" projective content.

(4) Only $[\text { Ken }]_{\mathrm{F}}$ sang. $\rightsquigarrow$ 'Ken sang.'

(5) Lucy believes that only [Ken $]_{F}$ sang.

$\psi$ 'Ken sang.'

$\rightsquigarrow$ 'Lucy believes that Ken sang.'

It is worth noting here that it may be simplistic to treat the OLE and SCF as categorical features. It has been pointed out in the literature (and acknowledged by Tonhauser et al. 2013: 101-102), for example, that the projective content induced by 
an additive focus particle may "leak" upward under certain configurations. Heim (1992) gives example (6) to illustrate that, when an additive particle is embedded under an attitude predicate, the additive implication could be understood to be part of the external speaker's commitments, rather than of the attitude holder's.

(6) (Two kids are talking to each other on the phone.)

John: I am already in bed.

Mary: My parents think $[\mathrm{I}]_{\mathrm{F}}$ am also in bed.

In a similar vein, it appears that sentence (3) is not to be deemed completely unacceptable in the discourse situation illustrated in (7).

(7) (A and B agree that Lucy has no idea about whether people other than Ken sang or not.)

A: So, who sang?

B: Let's see. John sang for sure. And Lucy believes that $[\text { Ken }]_{F}$ sang, too.

It seems impossible, on the other hand, to interpret the prejacent implication of only occurring in the complement clause of a belief predicate as a commitment of the external speaker; i.e., there cannot be upward leaking in this case.

It is also interesting to consider, in this connection, the case of the implicational verb manage (Oshima 2006a: 180-182); when this trigger is embedded under a belief predicate, the "difficulty" implication can easily be understood to be a commitment of the attitude holder; however, the alternative interpretation elicited in (9), where this implication is part of the speaker's commitments, appears not to be ruled out.

(8) Lucy believes that Ken will manage to beat Bill.

$\rightsquigarrow$ 'Lucy believes that it will be difficult for Ken to beat Bill.'

OR: $\rightsquigarrow$ 'It will be difficult for Ken to beat Bill.'

(9) Although Ken has been doing quite well in this year's contest, I don't think he has much chance of winning against John, the last year's champion, in the game tomorrow. Lucy, however, is convinced that Ken is the absolute best. She thus naturally believes that Ken will manage to beat Bill.

Furthermore, with manage, it seems that projection to the global level is easier than in the case of toolalso. These observations suggest that the OLE is a matter of continuum - some projective contents are completely obligatorily local, others are more or less obligatorily local, and so on.

A similar point applies to the SCF feature. While distinguishing Class $\mathrm{C}$ content from classical presupposition (= Class A content) is a major advance over the 
The meanings of perspectival verbs

simple dichotomy between regular entailment and presupposition, in practice it is not a straightforward matter to decide whether a given projective meaning (i) is presuppositional but can be (globally or locally) accommodated, or (ii) is not subject to the SCF constraint in the first place. A case in point is the factive implication of know. While Tonhauser et al. treat it as a Class $\mathrm{C}$ content, one could alternatively consider that it is a Class A content that is, for some reason, easier to accommodate than the additive implication of too. It seems sensible to suspect that the SCF feature, too, is of a continuous nature; some projective contents are strongly presuppositional (and are impossible or hard to accommodate), others are mildly so (and can be easily accommodated) and yet others are not presuppositional at all.

Having said these, in what follows I accept the premise that the $[ \pm$ OLE] and $[ \pm \mathrm{SCF}]$ features are valid ways to classify projective contents. They may be simplistic to a certain extent, but nevertheless are useful descriptive notions.

The meanings of appositives, nonrestrictive relative clauses (NRRC's), and expressives are $[-\mathrm{OLE}]$ and $[-\mathrm{SCF}]$, and thus fall under Class B. To illustrate the [-SCF] status of an NRRC, (10) can be a felicitous utterance despite the content of the NRRC not being part of the interlocutors' common ground.

(10) (S(peaker) assumes that H(earer) does not know anything about the author Yasunari Kawabata.)

I have translated several works by Yasunari Kawabata, who was awarded a Nobel Prize in literature in 1968.

$\rightsquigarrow$ 'Kawabata was awarded a Nobel Prize in literature in 1968.'

Example (11) illustrates the [-OLE] status of an NRRC. (11a) naturally allows a reading which commits the speaker to the truth of Ken's being a car sales representative. (11b), on the other hand, naturally allows a reading where Ken's being a spy is to be taken as part of Lucy's beliefs (Amaral, Roberts \& Smith 2007; cf. Harris \& Potts 2009).

(11) Lucy is mentally disturbed. She believes that Ken, who is \{a. an ordinary car sales representative / b. a trained spy $\}$, is tapping her phone.

a. $\rightsquigarrow$ 'Ken is an ordinary car sales representative.'

(OR, less plausibly: $\rightsquigarrow$ 'Lucy believes that Ken is an ordinary car sales representative.')

b. $\rightsquigarrow$ 'Lucy believes that Ken is a trained spy.'

(OR, less plausibly: $\rightsquigarrow$ 'Ken is a trained spy.')

Tonhauser et al.'s (2013) Class D includes the implication induced by a focus that there are contextually salient alternative propositions, and the implication induced by a demonstrative that the speaker is indicating (e.g., demonstrating) some entity. 
(12) $[\text { Wilma }]_{F}$ called Fred.

$\rightsquigarrow$ 'There is at least one contextually salient proposition of the form " $X$ called Fred" and is distinct from "Wilma called Fred".'

(13) Ken likes that car.

$\rightsquigarrow$ 'S is indicating something.'

(14) illustrates the [-OLE] status of the "indication" implication of a demonstrative.

(14) Lucy believes that Ken likes that car.

$\rightsquigarrow$ 'S is indicating something.'

$\not \rightarrow$ 'Lucy believes that S (or some other individual) is indicating something.'

The Class D contents taken up by Tonhauser et al. (2013) seem to be of a rather different nature from the other kinds of projective contents that they discuss, in being concerned with the proper usage of linguistic expressions than with the description of the state of affairs, or, in being metalinguistic rather than descriptive. One may that find it more sensible to treat them as part of the linguistic convention, rather than of conventionally coded meaning (I will not attempt to argue for either position here).

\section{A more elaborate taxonomy}

One limitation of Tonhauser et al.'s (2013) taxonomy is that it does not consider the "obligatory global effect". [-OLE] contents can be further classified into two subtypes: those that are obligatorily global, and those that are optionally global. I propose to classify projective content/conventional implicature (recall that these two notions are equated in the current work) into six classes, based on the criteria summarized in (15) and Table 2:

(15) i. Context-Checking (presuppositional, uninformative; $\approx[+\mathrm{SCF}]$ ) vs. Context-Updating (nonpresuppositional, potentially informative; $\approx[-\mathrm{SCF}])$

ii. Local-Context Oriented (LCO; $\approx[+\mathrm{OLE}])$ vs. Ambioriented vs. GlobalContext Oriented (GCO)

Tonhauser et al.'s Classes A and C quite straightforwardly correspond to my Classes (i) and (ii). The Class D contents discussed by Tonhauser et al. (2013) (e.g., the "indication" implication of a demonstrative) always need to be satisfied in the global context of evaluation, and fall under my Class (v).

As discussed earlier, when an NRRC, which is a Class B trigger according to Tonhauser et al.'s (2013), is embedded under a belief predicate, its content can be 
The meanings of perspectival verbs

\begin{tabular}{lccc}
\hline & LCO & Ambioriented & GCO \\
\hline \hline Context-Checking & (i) & (iii) & (v) \\
\hline Context-Updating & (ii) & (iv) & (vi) \\
\hline
\end{tabular}

Table 2 The proposed taxonomy of projective content/conventional implicature

interpreted either as a commitment of the external speaker, or of the secondary agent (the holder of the belief). The same happens to appositives and expressives (Amaral et al. 2007), as well. This makes them [Ambioriented] and [Context-Updating], i.e., Class (iv) contents.

The distinction between [Global-Context Oriented] and [Ambioriented] is useful even if all we need to consider is the kinds of projective content triggers taken up by Tonhauser et al.; their four-way distinction is too coarse to capture the fact that, for example, the meaning of an NRRC (Class B) and the "indication" implication of a demonstrative (Class D) differ not only in terms of presuppositoinality ( $[ \pm \mathrm{SCF}]$ ), but also in that only the latter is obligatorily anchored to the global context (i.e., is [GCO]). Also, one may treat the "difficulty" implication of manage as a Class D content, but it contrasts quite clearly from the Class D contents taken up by Tonhauser et al., again, in terms of whether they can be anchored to the local context or not (i.e., is [Ambioriented] or not).

In the following, I will illustrate that the meanings of perspectival verbs provide further motivation for the more fine-grained taxonomy proposed above. The perspectival meanings of deictic motion verbs (in English) and empathy-loaded verbs (in Japanese) will be shown to be Class (iii) contents. Those of referent-honorific verbs (in Japanese) will be shown to be Class (v).

\section{Formulation of the [Context-Checking]/[Context-Updating] features}

As a preliminary to the discussion of perspectival verbs, I illustrate in this section the format of semantic representation that I will utilize.

The proffered content and (nonpresuppositional and presuppositional) projective content play different roles in sentence meaning, and thus can be regarded to constitute distinct components/layers/dimensions of linguistically coded meaning. Nevertheless, semantic interactions, such as anaphoric relations, across these components are possible (Karttunen \& Peters 1979; Amaral et al. 2007; AnderBois, Brasoveanu \& Henderson 2013).

Multidimensional approaches to semantic representation, such as the ones developed by Karttunen \& Peters (1979) and Potts (2005), account for the first fact, 
but have trouble dealing with the second. I adopt what can be called a pseudomultidimensional system of semantic representation, where (i) proffered content, (ii) nonpresuppositional CI, and (iii) presuppositional CI are represented within a single logical expression, but nevertheless contribute to the pragmatic import of the utterance in distinct ways. This system is an extension of Oshima's (2006a,b) "truth-combination" system.

The basic ideas are as follows. I introduce a ternary operator called transjunction, and distinguish two levels of truth values. The first is the classic values of type $t, 1$ and 0 , for logical formulas of the familiar kind; they will be referred to as semantic truth values. The second is the pragmatic truth values, namely I, II, and III, which are respectively concerned with "truth of proffered content", "satisfaction of nonpresuppositional CI" and "satisfaction of presupposition(al CI)". The extension of a root declarative clause will be understood to be a set of pragmatic truth values, rather than an individual (semantic or pragmatic) value. A new semantic type, $T$, for a set of pragmatic truth values, is introduced. The syntax and semantics of transjunction are defined as follows:

The syntax and semantics of transjunction syntax:

If $\phi, \psi$, and $\chi$ are expressions of type $t\left(\mathbf{D}_{t}=\{1,0\}\right)$, then $\langle\phi ; \psi ; \chi\rangle$ is an expression of type $T\left(\mathbf{D}_{T}=\wp(\{\mathrm{I}, \mathrm{II}, \mathrm{III}\})\right)$.

semantics:

i. $\quad \mathrm{I} \in \llbracket\langle\phi ; \psi ; \chi\rangle \rrbracket^{\mathrm{g}}$ iff $\llbracket \phi \rrbracket^{\mathrm{g}}=1$,

ii. $\quad$ II $\in \llbracket\langle\phi ; \psi ; \chi\rangle \rrbracket^{\mathrm{g}}$ iff $\llbracket \psi \rrbracket^{\mathrm{g}}=1$, and

iii. III $\in \llbracket\langle\phi ; \psi ; \chi\rangle \rrbracket^{\mathrm{g}}$ iff $\llbracket \chi \rrbracket^{\mathrm{g}}=1$.

A root declarative clause generally denotes a function from Kaplanian contexts to functions from worlds to sets of pragmatic truth values. Sentence (17a), which I take to involve no nontrivial CI, will translate into (17b); $\mathbf{T}$ is a logical constant that is mapped to semantic truth value 1 under any assignment.

a. I admire Hemingway.

b. $\lambda c[\lambda w[\langle\operatorname{admire}(w, \boldsymbol{A g}(c), \operatorname{hemingway}) ; \mathbf{T} ; \mathbf{T}\rangle]]$

Sentence (18a), which involves the nonpresuppositional CI: 'Kawabata is a Japanese novelist' and the presuppositional CI: 'I admire someone other than Kawabata', will translate into (18b).

a. I also admire $[\text { Kawabata }]_{F}$, a Japanese novelist.

b. $\lambda c[\lambda w[\langle\operatorname{admire}(w, \boldsymbol{A g}(c), \operatorname{kawabata}) ; \boldsymbol{j a p a n e s e}-\operatorname{movelist}(w, \mathbf{k a w a b a t a}) ;$ $\exists x[x \neq \mathbf{k a w a b a t a} \wedge \operatorname{admire}(w, \operatorname{Ag}(c), x)]\rangle]]$ 
The meanings of perspectival verbs

The context change potential - or pragmatic contribution - of a root declarative clause will be as in (19); Cx (or Context with capital C) is the context in the dynamicsemantic sense, which I take here to be a set of triples of Kaplanian contexts (c), worlds (w), and assignments (g).

\section{The context change potential of a root declarative clause}

Let $\alpha$ be a root declarative clause whose logical form is $\Phi$ ( $=\lambda c[\lambda w[\langle\phi ; \psi ; \chi\rangle]])$. Then, $\mathrm{Cx}+\alpha$ is defined only if:

i. for all $\langle\mathrm{c}, \mathrm{w}, \mathrm{g}\rangle \in \mathrm{Cx}, \mathrm{III} \in \llbracket \Phi \rrbracket^{\mathrm{g}}(\mathrm{c})(\mathrm{w})$,

ii. there is at least one $\langle\mathrm{c}, \mathrm{w}, \mathrm{g}\rangle \in \mathrm{Cx}$ such that $\mathrm{II} \in \llbracket \Phi \rrbracket^{\mathrm{g}}(\mathrm{c})(\mathrm{w})$, and

iii. there is at least one $\langle\mathrm{c}, \mathrm{w}, \mathrm{g}\rangle \in \mathrm{Cx}$ such that $\mathrm{I} \notin \llbracket \Phi \rrbracket^{\mathrm{g}}(\mathrm{c})(\mathrm{w})$.

If defined, $\mathrm{Cx}+\alpha=\mathrm{Cx}^{\prime}$ such that $\mathrm{Cx}^{\prime} \subseteq \mathrm{Cx}$ and for all $\langle\mathrm{c}, \mathrm{w}, \mathrm{g}\rangle \in \mathrm{Cx}$, $\{\mathrm{I}, \mathrm{II}\} \subseteq \llbracket \Phi \rrbracket^{\mathrm{g}}(\mathrm{c})(\mathrm{w})$

Clause (i) in (19) dictates that the presupposition (i.e., the [Context-Checking] CI) must have been part of the common ground prior to the utterance. Clause (ii) dictates that the [Context-Updating] CI must not impose false information. Clause (iii), finally, dictates that the proffered content must be informative. Whether the third clause should be part of the definition of a context change potential will be debatable, as in actual conversations it is not uncommon for a speaker to make a statement whose proffered content is assumed to be known to the hearer (e.g., "Come on, you are not a five-year-old kid."). On the other hand, intuitively, (20a) is likely to sound redundant and odd in situation (21a) but not (21b), and (20b) is likely to sound redundant and odd in situation (21b) but not (21a); both $(20 a, b)$ are fine in situation (21c). Clause (iii) will be useful to account for this pattern.

(20) a. I admire Obama, (who is) the 44th President of the U.S.

b. Obama, who I admire, is the 44th President of the U.S.

a. It is common ground that $\mathrm{S}$ admires Obama, and it is not common ground that Obama is the 44th U.S. president.

b. It is common ground that Obama is the 44th U.S. president, and it is not common ground that $\mathrm{S}$ admires Obama.

c. It it not common ground S admires Obama, or that Obama is the 44th U.S. president.

Anyhow, according to (19), utterance (18a) will be felicitous only if (i) the Context gurantees that $\mathrm{S}$ admires Kawabata, and (ii) the Context is compatible with the information that Kawabata is a Japanese novelist, and (iii) the Context is compatible with the information that $\mathrm{S}$ does not admire Kawabata. 


\section{Motion-deictic verbs and empathy-loaded verbs as Class (iii) CI triggers}

In Oshima (2006a,b), it was argued that the "not-at-issue" meanings of motiondeictic verbs (e.g., English go/come) and empathy-loaded verbs (e.g, Japanese yaru/ kureru 'give') make reference to a contextual component - the RP, a set of entities serving as potential reference points, for the former, and the ER, a poset of entities based on the empathy relation (" $a$ receives a higher degree of empathy than $b$ ") for the latter. Furthermore, these components can either be part of the global or local context, which implies that these perspectival verbs are "all-purpose indexicals" in Schlenker's (2003) sense.

\subsection{Motion-deictic verbs}

Roughly, go conveys (as a CI) that no member of the RP is located at the destination of the motion at the utterance time, and come conveys (as a $\mathrm{CI}$ ) that at least one member of the RP is located at the destination either at the utterance time or at the event time. With data like the following, it can be shown that the CI induced by a deictic motion verb is presuppositional, i.e., [Context-Checking] (cf. Barlew 2014).

(22) In the 1990s I would tour all around North America as a stand-up comedian. One day, \#(when I was staying in Austin,) my brother, who was then a graduate student, came to University of Texas to attend an academic conference.

To illustrate the ambiorientedness of the CI induced by a deictic motion verb, (23) may convey either (24a) or (24b) as a CI, so that it can be felicitous either in situation (25a) or (25b).

(23) Lucy believes that Ken came to Chicago.

(24) a. Some member of the RP (in the global context) - which is most likely $\{\mathrm{S}, \mathrm{H}\}-$ is or was located in Chicago.

b. Lucy believes that some member of the RP (in the local context) - which is most likely $\{$ Lucy $\}$ - is or was located in Chicago.

a. $\mathrm{S}$ and $\mathrm{H}$ agree (i) that they are and were in Chicago, and (ii) that Lucy believes that she is and was in Austin.

b. $\mathrm{S}$ and $\mathrm{H}$ agree (i) that they are and were in Austin, and (ii) that Lucy believes that she is and was in Chicago.

The logical forms corresponding to the two readings of (23) will be along the lines of $(26 a, b)$ :

a. $\lambda c\left[\lambda w\left[\left\langle\forall\left\langle c^{\prime}, w^{\prime}\right\rangle \in \operatorname{Dox}(w\right.\right.\right.$, lucie $)\left[\operatorname{move-to}\left(w^{\prime}\right.\right.$, ken, chicago $\left.)\right] ; \mathbf{T} ;$

$\exists x[x \in \mathbf{R P}(c) \wedge$ at $(w, x$, chicago $)]\rangle]]$ 
The meanings of perspectival verbs

b. $\lambda c\left[\lambda w\left[\left\langle\forall\left\langle c^{\prime}, w^{\prime}\right\rangle \in \operatorname{Dox}(w\right.\right.\right.$, lucie $)\left[\operatorname{move-to}\left(w^{\prime}\right.\right.$, ken, chicago $\left.)\right] ; \mathbf{T}$; $\forall\left\langle c^{\prime}, w^{\prime}\right\rangle \in \operatorname{Dox}(w$, lucie $)\left[\exists x\left[x \in \mathbf{R P}\left(c^{\prime}\right) \wedge\right.\right.$ at $\left(w^{\prime}, x\right.$, chicago $\left.\left.\left.\left.)\right]\right]\right\rangle\right]$

\subsection{Empathy-loaded verbs}

Linguistic empathy, as Kuno (1987: 206) defines it, is an agent's “identification, which may vary in degree, with a person or thing"; it is reflected in language in a number of ways, and is sometimes encoded lexically or grammatically.

Paradigmatic examples of empathy-loaded expressions are the Japanese giving verbs yaru (and its stylistic variant ageru) and kureru, both of which map the donor participant to the subject, and thus translate into English give. Yaru conveys that the relevant agent (most typically the speaker) empathizes with the donor at least to the same extent as with the recipient, while kureru conveys that she empathizes with the recipient to a greater extent than with the donor. Put differently, yaru implicates that the donor does not outrank the recipient on the contextually relevant ER (i.e., the poset based on the degree of empathy), and kureru implicates that the donor is outranked by the recipient on the ER. ${ }^{1}$

Ken-ga Mari-ni sono hon-o $\quad\{$ a. yatta/b. kureta $\}$.

K.-Nom M.-Dat that book-Acc yaru.Pst/kureru.Pst

'Ken gave Mari that book.'

a. $\rightsquigarrow$ 'Ken does not outrank Mari on the ER.'

b. $\rightsquigarrow$ 'Ken is outranked by Mari on the ER.'

In a root environment, the relevant agent is the speaker, and accordingly the speaker is invariably the greatest element of the ER. In consequence, yaru must be chosen when the speaker is the donor, and kureru will be the only possible choice when the speaker is the recipient.

a. Boku-ga Ken-ni sono hon-o $\quad$ yatta/\#kureta .

I-Nom K.-Dat that book-Acc yaru.Pst/kureru.Pst

'I gave Ken that book.'

b. Ken-ga boku-ni sono hon-o $\quad$ \#yatta/kureta .

K.-Nom I-Dat that book-Acc yaru.Pst/kureru.Pst

'Ken gave me that book.'

1 The abbreviations in the glosses are: Acc $=$ accusative, Attr $=$ attributive, Comp $=$ complementizer, Cond $=$ conditional, Cop $=$ copula, Dat $=$ dative, DAux $=$ discourse auxiliary, DP $=$ discourse particle, Evid = evidential auxiliary, Gen = genitive, Ger = gerund, Hon = honorific, Inf = infinitive, Loc $=$ locative, $\operatorname{Neg}($ Aux $)=$ negation (auxiliary), Nom = nominative, Npfv = nonperfective auxiliary, NSHon $=$ non-subject honorific, $\mathrm{Plt}=$ polite, Pot $=$ potential, Prs $=$ present, Pst $=$ past, SHon $=$ subject honorific, $\mathrm{Th}=$ thematic $w a$ (topic/ground marker). 
Yaru and kureru can also be used as benefactive auxiliary verbs, in which case they respectively indicate that the beneficiary does not outrank and outranks the benefactor on the ER.

(29) Ken-ga Mari-o oshite $\quad\{$ a. yatta/b. kureta $\}$.

K.-Nom M.-Acc push.Ger yaru.Pst/kureru.Pst

'Ken pushed Mari for her sake.'

$\rightsquigarrow$ 'Ken's pushing Mari was beneficial for Mari.' (benefactive CI)

a. $\rightsquigarrow$ 'Ken does not outrank Mari on the ER.' (empathic CI)

b. $\rightsquigarrow$ 'Ken is outranked by Mari on the ER.' (empathic CI)

The benefactive and empathic meanings of yaru and kureru as auxiliaries are both projective; the former is arguably a Class (i) content, and will be put aside in what follows. With data like (30), it can be shown that the empathic CI induced by an empathy-loaded verb is presuppositional (note that the speaker's close relatives are expected to recieve a high degree of empathy).

(30) (S and $\mathrm{H}$ are acquainted but not close.)

a. Sengetsu, saifu-o nakushite komatte iru ryokoosha-o last.month wallet-Acc lose.Ger be.troubled.Ger Npfv.Prs traveler-Acc tasukete \{yarimashita/\#kuremashita $\}$-yone? (Jitsuwa, are-wa help.Ger yaru.Pst.Plt/kureru.Pst.Plt-DP actually that-Th watashi-no otooto na ndesu.) I-Gen little.brother Cop.Attr DAux.Prs.Plt

'You helped out last month a traveler who lost his wallet and was in trouble, didn't you? (Actually, that is my little brother.)'

b. Sengetsu, saifu-o nakushite komatte iru last.month wallet-Acc lose.Ger be.troubled.Ger Npfv.Prs otooto-o tasukete $\{$ ??yarimashita/kuremashita $\}$-yone? little.brother-Acc help.Ger yaru.Pst.Plt/kureru.Pst.Plt-DP

'You helped out last month my little brother, who lost his wallet and was in trouble, didn't you?'

Linguistic manifestation of the empathy relation is a broad phenomenon. As discussed in Oshima (2007a), the direct/inverse opposition (or "syntactic direction") of transitive verbs in such languages as Cree, Navajo, and Jinghpaw, can be taken to be a grammatical means to express the empathy relation between the participants in a more systematic way than the Japanese yaru/kureru opposition does. Empathy is also concerned with the obviation marking on third-person nominals in Cree 
The meanings of perspectival verbs

(Oshima 2007a), as well as the licensing of certain kinds of long-distance anaphors (e.g. Japanese jibun, English self-pronouns; Oshima 2007b).

It has been pointed out in the literature that in an (indirect) reported discourse environment, an empathy-loaded verb can be interpreted either with respect to the external speaker's (the primary agent's) or with respect to the attitude holder's (the secondary agent's) perspective (Oshima 2006a and references therein). ${ }^{2}$

a. Boku-ga Ken-o tetsudatte $\{$ yaru/\#kureru $\}$.

I-Nom K.-Acc help.Ger yaru.Prs/kureru.Prs

'I will give Ken a hand.'

b. Ken-wa [boku-ga tetsudatte yaru] to omotte iru. K.-Th I-Nom help.Ger yaru.Prs Comp believe.Ger Npfv.Prs

'Ken believes that I will give him a hand.' (primary perspective)

c. Ken-wa [boku-ga tetsudatte kureru] to omotte iru. K.-Th I-Nom help.Ger kureru.Prs Comp believe.Ger Npfv.Prs 'idem' (secondary perspective)

(32) a. Ken-no otooto-ga boku-o tetsudatte $\{\#$ yatta/kureta $\}$. K.-Gen little.brother-Nom I-Acc help.Ger yaru.Pst/kureru.Pst 'Ken's brother gave me a hand.'

b. $\mathrm{Ken}_{i}$-wa [ $\mathrm{kare}_{i}$-no otooto-ga boku-o tetsudatte kureta] K.-Th he-Gen little.brother-Nom I-Acc help.Ger kureru.Pst to omotte iru.

Comp believe.Ger Npfv.Prs

'Ken ${ }_{i}$ believes that his ${ }_{i}$ brother gave me a hand.' (primary perspective)

c. $\mathrm{Ken}_{i}$-wa [jibun $i$-no otooto-ga boku-o tetsudatte yatta] to K.-Th self-Gen little.brother-Nom I-Acc help.Ger yaru.Pst Comp omotte iru. believe.Ger Npfv.Prs

'idem' (secondary perspective)

This implies that the empathic meanings induced by yaru/kureru are ambioriented. Sentence (33) allows two interpretations illustrated in (34) ("outrank $(a, b, P)$ " is read as " $a$ outranks $b$ on the poset $P$ "); (34a) will be more plausible if Mari and Yumi are respectively Ken's and the speaker's sister, and (34b) will be more plausible in the converse situation.

2 In (32), the choice of the anaphoric expression kare facilitates the choice of kureru, and the choice of jibun facilitates the choice of kureru. This has to do with the perspective-sensitivity of jibun; see Oshima (2006a) for discussion. 
(33) Ken-wa [Mari-ga Yumi-o tetsudatte kureta] to omotte iru. K.-Th M.-Nom Y.-Acc help.Ger yaru.Prs Comp believe.Ger Npfv.Prs 'Ken believes that Mari gave Yumi a hand.'

a. $\lambda c\left[\lambda w\left[\left\langle\forall\left\langle c^{\prime}, w^{\prime}\right\rangle \in \operatorname{Dox}(w, \operatorname{ken})\left[\right.\right.\right.\right.$ give-a-hand $\left(w^{\prime}\right.$, mari, yumi $\left.)\right]$; $\mathbf{T}$; outrank (yumi, mari, $\mathbf{E R}(c))\rangle]]$

b. $\lambda c\left[\lambda w\left[\left\langle\forall\left\langle c^{\prime}, w^{\prime}\right\rangle \in \operatorname{Dox}(w, \operatorname{ken})\left[\right.\right.\right.\right.$ give-a-hand $\left(w^{\prime}\right.$, mari, yumi $\left.)\right]$; T; $\left.\left.\left.\forall\left\langle c^{\prime}, w^{\prime}\right\rangle \in \operatorname{Dox}(w, \operatorname{ken})\left[\operatorname{outrank}\left(\mathbf{y u m i}, \operatorname{mari}, \operatorname{ER}\left(c^{\prime}\right)\right)\right]\right\rangle\right]\right]$

\section{Honorifics as Class (iv) CI triggers}

Japanese referent-honorific predicates, which are regarded as CI triggers by Potts \& Kawahara (2004) and McCready (2010), can be classified into (i) subject honorifics, which express respect toward the referent of the subject (the least oblique argument), and (ii) non-subject honorifics, which express respect toward the referent of the second least oblique argument.

a. Yamada-kyooju-wa Osaka-ni osumaida.

Y.-professor-Th O.-Dat live.SHon.Prs

'Prof. Yamada (who I honor) lives in Osaka.'

b. Ken-ga Yamada-kyooju-o otetsudaishita.

K.-Nom Y.-professor-Acc help.NSHon.Pst

'Ken assisted Prof. Yamada (who I honor).'

For the appropriate use of a referent-honorific, it must be taken for granted or at least be easily inferrable that the relevant referent is honored by the speaker.

(36) (A and B work at the same hotel. A mentions a man who made a scene at a café across the street. B has seen him, and realized that the man was a professor of his college days.)

A: Kimi-wa sawagi-o okoshita otoko-o mita-no?

you-Th disturbance-Acc cause.Pst man-Acc see.Pst-DAux.Prs

'Did you see the man who made the scene?'

B: Ee, okane-o \{motte nai /\#omochide nai

yes, money-Acc have.Ger Npfv.Neg.Prs have.SHon.Inf NegAux.Prs

noni shokuji-o $\{$ shita / \#sareta $\}$ yoodesu.

although meal-Acc do.Pst do.SHon.Pst Evid.Prs.Plt

'Yes, from what I heard, he had a meal although he did not have money.' 
The meanings of perspectival verbs

The use of honorifics in (36B) would be acceptable if B first informed A of the relation between him and the man in question. It can be concluded, thus, that an honorific CI is presuppositional (i.e., [Context-Checking]).

Japanese referent-honorific predicates, although deictic in a broad sense (i.e., social-deictic), exhibit an interesting contrast with the two classes of perspectival verbs discussed in Section 6. That is, their honorific (social-deictic) meanings always, rather than optionally, project through a belief predicate. (37) illustrates this point.

(37) (Sota Kubo is the president of a company, and his son Akio Kubo is an executive director. Toru Noda is a young employee working under Akio.)

a. (an utterance by Toru Noda)

Shacho-wa [goshisoku no Akio-sama-ga Osaka-ni \{??sunde

president-Th son.Hon Cop.Attr A.-Suffix-Nom O.-Dat live.Ger

iru / osumaida $\}$ ] to omotte irassharu.

Npfv.Prs live.SHon.Prs Comp believe.Ger Npfv.SHon.Prs

'The president (who I honor) believes that his son Akio (who I honor) lives in Osaka.'

b. (an utterance by Sota Kubo)

Noda Toru-kun-wa [ore-no segare-ga Kobe-ni \{sunde iru /

N. T.-Suffix-Th I-Gen son-Nom K.-Dat live.Ger Npfv.Prs

\#osumaida $\}$ ] to omotte iru.

live.SHon.Prs Comp believe.Ger Npfv.Prs

'Toru Noda believes that my son lives in Osaka.'

(37b) with osumaida is deemed to be odd because this embedded honorific predicate can only be interpreted as expressing Sota's respect toward his son Akio, and this contradicts the social norms (according to which a father does not "honor" his son as long as the usage of referent honorifics is concerned). That is, (37b) with osumaida can have the meaning illustrated in (38a), but not the one illustrated in (38b).

a. $\lambda c\left[\lambda w\left[\left\langle\forall\left\langle c^{\prime}, w^{\prime}\right\rangle \in \operatorname{Dox}(w, \operatorname{toru})\left[\operatorname{live}\left(w^{\prime}\right.\right.\right.\right.\right.$, akio, kobe $\left.)\right]$; T; $\operatorname{honor}(\operatorname{Ag}(c)$, akio $)\rangle]]$

b. $\lambda c\left[\lambda w\left[\left\langle\forall\left\langle c^{\prime}, w^{\prime}\right\rangle \in \operatorname{Dox}(w\right.\right.\right.$, toru $)\left[\operatorname{live}\left(w^{\prime}\right.\right.$, akio, kobe $\left.)\right]$; T; $\forall\left\langle c^{\prime}, w^{\prime}\right\rangle \in \operatorname{Dox}(w, \operatorname{toru})\left[\operatorname{honor}\left(\operatorname{Ag}\left(c^{\prime}\right)\right.\right.$, akio $\left.\left.\left.\left.)\right\rangle\right]\right]\right]$

It is also worth mentioning that when a honorific verb occurs in the consequent of a conditional, its presuppositional meaning can only be understood to target 
the global (original) common ground, rather than the common ground temporarily augmented by the content of the antecedent. ${ }^{3}$

(39) (The interlocutors are eating at a local ramen restaurant. S is H's senior colleague.)

Kimi-ga koozoku dattara, konna tokoro-de raamen-wa you-Nom imperial.family Cop.Cond like.this place-Loc ramen.noodles-Th \{taberarenai/\#meshiagarenai . eat.Neg.Pot.Prs/eat.SHon.Neg.Pot.Prs

'If you were a member of the Imperial Family, you would not be able to eat ramen at a place like this.'

This contrasts with the case of a Class (i) content, which invariably targets the augmented common ground.

(40) \{There are several people, including Ken, in the room. / \#Ken, and nobody else, is in the room. $\}$ If Ken were not in the room, then Lucy would be there

too.

$\not \rightarrow$ 'There is somebody other than Lucy in the room in actuality.'

$\rightsquigarrow$ '(Even) if Ken were not in the room, there (still) would be somebody other than Lucy in the room.'

Based on the observations made above, it can be concluded that referent honorifics are Class (v) CI triggers.

\section{Conclusion}

Projective content (conventional implicature, "not-at-issue" meaning) can usefully be divided into six classes, based on the opposition of [Context-Checking] vs. [ContextUpdating] and the opposition of [Local-Context Oriented], [Ambioriented], and [Global-Context Oriented].

i. [Context-Checking]/[Local-Context Oriented] "classical" presuppositions; e.g., also (additive implication)

ii. [Context-Updating]/[Local-Context Oriented] "informative" presuppositions; e.g., only (prejacent implication)

3 It is interesting to ask how the CI's induced by motion-deictic verbs and empathy-loaded verbs occurring within the consequent of a conditional may project and be filtered. This issue is left for future research. 
The meanings of perspectival verbs

iii. [Context-Checking]/[Ambioriented] e.g., manage ("difficulty" implicaton), deictic motion verbs, empathyloaded verbs

iv. [Context-Updating]/[Ambioriented] e.g., appositives, NRRCs, expressives

v. [Context-Checking]/[Global-Context Oriented] e.g., demonstratives ("indication" implication), referent honorific verbs

vi. [Context-Updating]/[Global-Context Oriented] (unknown)

It is interesting to ask whether further instances can be added to each of Classes (i)-(v), and whether any can be found that belongs to Class (vi). Gender specification of pronouns (e.g., Yanovich 2012), for example, will be a controversial case.

\section{References}

Abusch, Dorit. 2002. Lexical alternatives as a source of pragmatic presuppositions. In Brendan Jackson (ed.), Semantics and Linguistic Theory (SALT) 12, 1-19. Ithaka, NY: CLC Publications.

Amaral, Patricia, Craige Roberts \& Allyn Smith. 2007. Review of The Logic of Conventional Implicatures by Chris Potts. Linguistics and Philosophy 30. 707-749. doi:10.1007/s10988-008-9025-2.

AnderBois, Scott, Adrian Brasoveanu \& Robert Henderson. 2013. At-issue proposals and appositive impositions in discourse. Journal of Semantics 32. 93-138. doi:10.1093/jos/fft014.

Barlew, Jefferson. 2014. Coming to a doxastic agent. In Eva Csipak \& Hedde Zeijlstra (eds.), Sinn und Bedeutung 19, 71-88. Göttingen: Georg-AugustUniversität Göttingen.

Beaver, David I. \& Brady Z. Clark. 2008. Sense and Sensitivity: How Focus Determines Meaning. Malden: Wiley-Blackwell.

Birner, Betty J. 2013. Introduction to Pragmatics. Malden: Wiley-Blackwell.

Harris, Jesee A. \& Christopher Potts. 2009. Perspective-shifting with appositives and expressives. Linguistics and Philosophy 32. doi:10.1007/s10988-010-9070-5.

Heim, Irene. 1992. Presupposition projection and the semantics of attitude verbs. Journal of Semantics 9. 183-221. doi:10.1093/jos/9.3.183.

Karttunen, Lauri \& Stanley Peters. 1979. Conventional implicature. In Choon-Kyu Oh \& David A. Dinneen (eds.), Presupposition, 1-56. New York: Academic Press.

Kuno, Susumu. 1987. Functional Syntax: Anaphora, Discourse, and Empathy. Chicago: The University of Chicago Press. 
McCready, Eric. 2010. Varieties of conventional implicature. Semantics and Pragmatics 3(8). 1-57. doi:10.3765/sp.3.8.

Oshima, David Y. 2006a. Perspectives in reported discourse. Stanford, CA: Stanford University PhD dissertation.

Oshima, David Y. 2006b. Motion deixis, indexicality, and presupposition. In Masayuki Gibson \& Jonathan Howell (eds.), Semantics and Linguistic Theory (SALT) 16, 172-189. Ithaka, NY: CLC Publications.

Oshima, David Y. 2007a. Syntactic direction and obviation as empathybased phenomena: A typological approach. Linguistics 45. 727-764. doi:10.1515/LING.2007.022.

Oshima, David Y. 2007b. On empathic and logophoric binding. Research on Language and Computation 5. 19-35. doi:10.1007/s11168-006-9020-0.

Oshima, David Y. 2012. GO and COME revisited: What serves as a reference point? In Zhenya Antić, Charles B. Chang, Emily Cibelli, Jisup Hong, Michael J. Houser, Clare S. Sandy, Maziar Toosarvandani \& Yao Yao (eds.), Berkeley Linguistics Society (BLS) 32 (General Session \& Parasession), 287-298. Berkeley, CA: Berkeley Linguistics Society.

Potts, Christopher. 2005. The Logic of Conventional Implicatures. Oxford: Oxford University Press.

Potts, Christopher \& Shigeto Kawahara. 2004. Japanese honorifics as emotive definite descriptions. In Kazuha Watanabe \& Robert B. Young (eds.), Semantics and Linguistic Theory (SALT) 14, 235-254. Ithaka, NY: CLC Publications.

Prince, Ellen F. 1978. A comparsion of $w h$-clefts and it-clefts in discourse. Language 54. 883-906. doi:10.2307/413238.

Schlenker, Philippe. 2003. A plea for monsters. Linguistics and Philosophy 26. 29-120. doi:10.1023/A:1022225203544.

Tonhauser, Judith, David Beaver, Craige Roberts \& Mandy Simons. 2013. Toward a taxonomy of projective content. Language 89. 66-109. doi:10.1353/lan.2013.0001.

Yanovich, Igor. 2012. Indexical presuppositions of pronominal gender features. Ms, Massachusetts Institute of Technology.

David Y. Oshima

Graduate School of International Development

Nagoya University

Nagoya, Japan 464-8601

davidyo@nagoya-u.ac.jp 